\title{
Margens Indomáveis: cogumelos como espécies companheiras ${ }^{1}$
}

\author{
Anna Tsing \\ Departamento de Antropologia, Universidade da Califórnia, Santa Cruz, Estados \\ Unidos \\ Tradução: Pedro Castelo Branco Silveira \\ Universidade Federal de Santa Catarina, SC, Brasil \\ Revisão de tradução: Thiago Mota Cardoso \\ Universidade Federal de Santa Catarina, SC, Brasil
}




\section{Resumo}

A natureza humana é uma relação entre espécies. Neste ensaio, o conceito de espécies companheiras de Donna Haraway nos leva além dos companheiros familiares, nos leva para a rica diversidade ecológica sem a qual os seres humanos não podem sobreviver. Aqui busca-se nosso alimento seguindo os fungos nos últimos dez mil anos de história de perturbação humana, em companhia multiespécies e feminista. Os cereais domesticam os seres humanos. As monoculturas nos dão as subespécies chamadas de raças. O lar isola o amor intraespécies do amor interespécies. Mas os cogumelos coletados nos levam para outro lugar: para as bordas indisciplinadas e as costuras do espaço imperial, onde não se pode ignorar as interdependências entre espécies que nos dão à vida na Terra. Há muita história para contar aqui, e tais histórias não devem ser deixadas para os triunfalistas humanos que controlam o campo. Este ensaio abre as portas para as paisagens multiespécies como protagonistas de histórias do mundo.

Palavras-chave: Etnografia Multiespécies. Fungos. Paisagem.

\section{Abstract}

Human nature is an interspecies relationship. In this essay, Haraway's concept of companion species takes us beyond familiar companions to the rich ecological diversity without which humans cannot survive. Following fungi, we forage in the last ten thousand years of human disturbance history with feminist multispecies company. Cereals domesticate humans. Plantations give us the subspecies we call race. The home cordons off inter-and intra-species love. But mushroom collecting brings us somewhere else - to the unruly edges and seams of imperial space, where we cannot ignore the interspecies interdependencies that give us life on earth. There are big stories to tell here, and they should not be left to the human triumphalists who control the field. This essay opens a door to multispecies landscapes as protagonists for histories of the world.

Keywords: Multispecies Ethnography. Fungi. Landscape. 


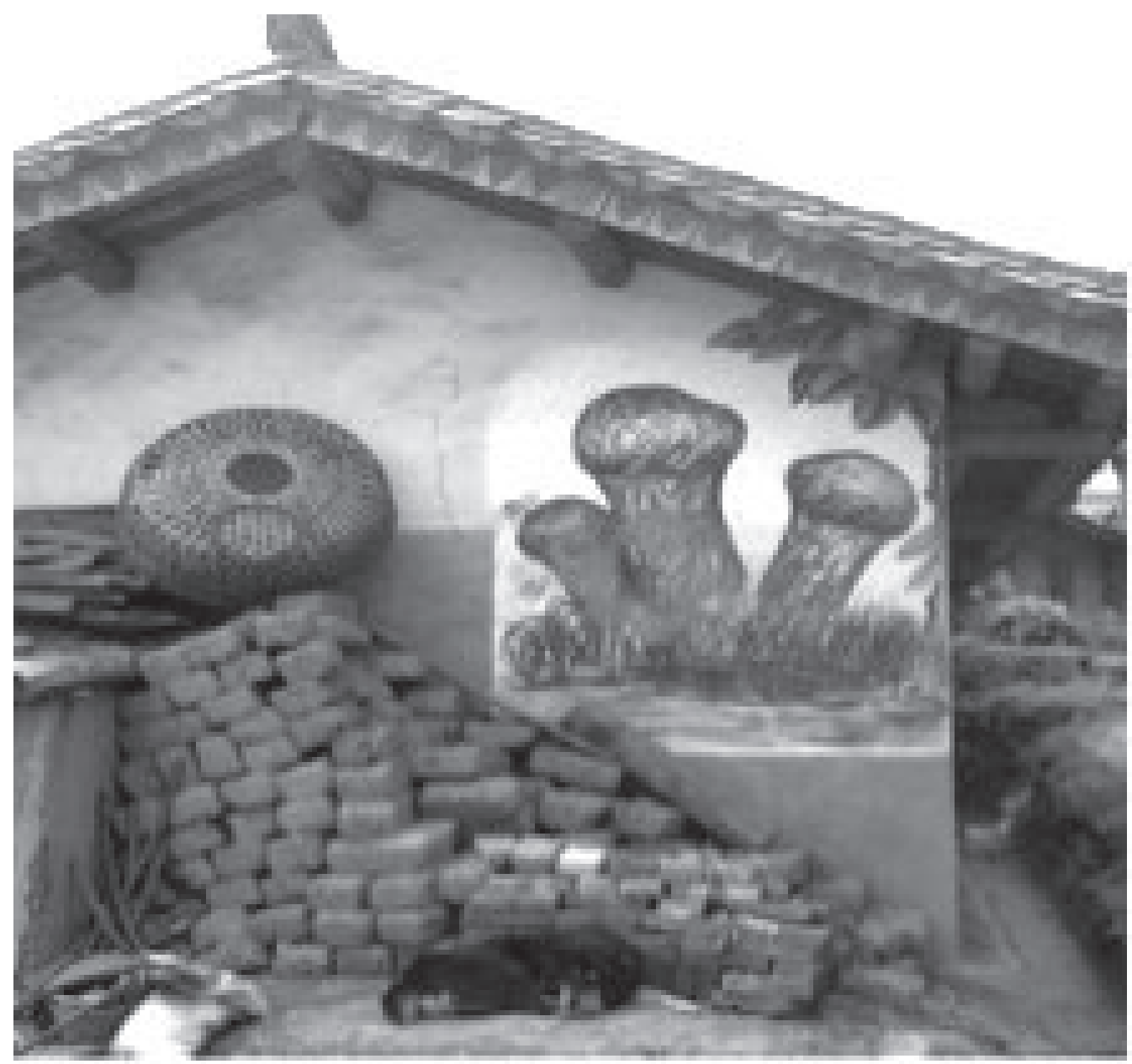

Figura 1: Yunnan, China. Cogumelos silvestres, carro-chefe da economia local, pintado aqui nas paredes de uma casa

Fonte: Anna Tsing, arquivo pessoal (fotografia gentilmente cedida pela autora para esta tradução) 


\section{Introdução}

dominação, a domesticação e o amor estão firmemente entre-
todas essas dependências intra e interespecíficas atingem o auge da
saturação. Por mais prazeroso que seja, talvez essa não seja a melhor
ideia para uma vida multiespécies na Terra. Considere, ao invés disso,
a abundante diversidade que margeia as estradas. Ou considere os
cogumelos.

Esse ensaio tem uma dívida com Donna Haraway (2003) não apenas pelo conceito de "espécies companheiras", mas também pela permissão que ela nos oferece de sermos ao mesmo tempo cientistas e críticos culturais, ou seja, de recusarmos as fronteiras que isolam natureza da cultura e, além disso, de ousarmos contar a história do mundo em uma única frase, ou certamente num ensaio curto ${ }^{2}$. Nesse espírito, meu ensaio inicia com uma experiência de companheirismo e biologia, antes de abordar a história da domesticação, da Conquista europeia, e dos potenciais da política e do biologicamente diverso nas costuras do capitalismo global. Esse material apresenta um argumento fúngico contra um ideal tão arraigado como o da domesticação, pelo menos o da domesticação de mulheres e de plantas.

\section{Cogumelos numa Paisagem Multiespécies}

Perambular e amar cogumelos são atividades que se retroalimentam. Caminhar é a velocidade do prazer corpóreo e da contemplação e é também a melhor velocidade para procurar cogumelos. Depois das chuvas o ar tem um cheiro fresco de ozônio, seiva e folhiço. Meus sentidos estão vívidos de curiosidade. Não há coisa melhor do que me deparar com as camadas laranja dos cantarelos ${ }^{3}$ (Cantharellus cibarius) penetrando na umidade escura. Ou com as bolotas quentes dos tortulhos (Boletus edulis) pipocando na terra esfarelenta. Cogumelos provocam a excitação da cor, da fragrância e do design, além do orgulho de quem é o primeiro a encontrá-los. Mas, dentre os prazeres que eles provocam, parece-me que os maiores são dois: primeiro, a recompensa generosa da dádiva; e, segundo, a oferta de um lugar que guiará as caminhadas 
futuras. Esses cogumelos não são produtos de meu trabalho, e pelo fato de eles não me terem exigido dedicação e cuidado, saltam às minhas mãos com todo o deleite do impensado e do inesperado. Por um momento, minha carga pesada de culpa é absolvida e, como uma ganhadora da loteria, estou iluminada com a doçura da vida. Bismillah irachman irachim ${ }^{4}$.

O prazer imprime uma marca: a impressão de um lugar. É a excitação dos meus sentidos que me traz à memória um conjunto de cores e tons, o ângulo da luz, as sarças espinhentas, o sólido aterramento da árvore e a subida do morro à minha frente. Muitas vezes, andando a esmo, repentinamente me lembrei de cada toco e de cada oco do lugar onde estava, inclusive dos cogumelos que um dia encontrei ali. Uma decisão consciente também pode me levar para pontos de encontros passados, já que a melhor forma de encontrar cogumelos é sempre voltar aos lugares onde você os achou antes. Em muitos casos, o corpo vegetativo (micélio), que sazonalmente frutifica cogumelos, persiste ao longo das estações; além disso, os corpos vegetativos de algumas espécies de cogumelos são companheiros vitalícios de árvores específicas. Se você quiser encontrar cantarelos na Califórnia central, você deve procurar sob os carvalhos. Mas não sob qualquer carvalho, você deve procurar "o" carvalho que vive com o micélio de cantarelos. Você o saberá por que já viu os cogumelos lá antes. Você visita aquele ponto o suficiente para conhecer as flores de cada estação e a atividade dos animais; você produziu um lugar familiar na paisagem. Lugares familiares são o início da apreciação das interações multiespécies.

A busca por alimento, ou forrageamento, funcionou exatamente desta forma na maior parte da história humana. Para encontrar uma planta, animal ou fungo útil, os forrageadores localizavam lugares familiares e retornavam a eles continuamente. Rifles superpotentes e superpopulação de peixes em reservatórios tornam possível matar algo com sucesso numa passagem aleatória pela zona rural; mas os caçadores e pescadores esportivos se dão ainda melhor com um guia local. Por meio de seus lugares familiares, os forrageadores aprendem não só sobre as relações ecológicas em geral, mas também sobre o acaso nas histórias naturais que permitiu que certas espécies e associações 
de espécies pudessem ocorrer em certos locais. Os lugares familiares de procura de alimento não requerem exclusividade territorial; outros seres, humanos ou não, também o aprendem. Suas geografias expansivas e sobrepostas resistem a modelos comuns que dividem o mundo em "seu espaço" e "o meu". Além disso, os forrageadores, mais do que se concentrarem em certas espécies individualizadas, atem-se às paisagens, com seus múltiplos residentes e visitantes. Lugares familiares implicam formas de identificação e companheirismo que contrastam com a hiperdomesticação e a propriedade privada nas formas em que conhecemos. Se você procura um mundo de companheiros mutuamente prósperos, considere os cogumelos.

Cogumelos são bem conhecidos como companheiros. O conceito de "simbiose" - convivência interespecífica mutuamente benéfica - foi inventado para o líquen, uma associação de um fungo com uma alga ou com uma cianobactéria. Nesta interação, o parceiro não-fúngico abastece o metabolismo do líquen por meio da fotossíntese; o fungo torna possível ao líquen viver em condições extremas. Ciclos repetidos de umidificação e dessecamento não perturbam o líquen, pois o parceiro fúngico pode reorganizar suas membranas logo que a água aparece, permitindo a continuidade da fotossíntese (Jennings; Lysek, 1999, p. 75$)^{5}$. Os líquens podem ser encontrados tanto na tundra gelada quanto em pedras ressecadas do deserto.

Para os amantes dos cogumelos, o companheirismo interespecífico mais intrigante ocorre entre fungos e raízes de plantas. Nas micorrizas, os filamentos do corpo fúngico entram nas raízes das plantas ou formam uma bainha ao seu redor. As plantas-cadáver (Monotropa uniflora) e outras plantas sem clorofila são mantidas exclusivamente dos nutrientes que recebem dos fungos em suas raízes (Christensen, 1965, p. 50); muitas orquídeas não podem nem mesmo germinar sem a assistência de fungos ${ }^{6}$. Nesses casos, as plantas tiram sustento dos fungos. Na maioria dos casos, entretanto, é o fungo que obtém sustento da planta. Mas os fungos de micorrizas não são egoístas quando se alimentam. Eles trazem água para a planta e tornam os minerais do solo, ao seu redor, disponíveis para seu hospedeiro. 
Os fungos podem também perfurar pedras, tornando seus elementos minerais disponíveis para o crescimento das plantas. Na longa história da Terra, os fungos são responsáveis por enriquecer os solos e assim permitir que as plantas evoluíssem. Há fungos que canalizam minerais das rochas para as plantas (Money, 2002, p. 60). Há árvores capazes de crescer em solos pobres por causa dos fungos que trazem fósforo, magnésio, cálcio e outros nutrientes às suas raízes. Na região onde eu vivo, os reflorestadores inoculam o fungo Suillus ao plantar mudas de abeto de Douglas (Pseudotsuga menziesii) para auxiliar no seu crescimento. Ao mesmo tempo, muitos dos mais valorizados cogumelos culinários são micorrizas. Na França, os produtores de trufas inoculam as mudas de árvores em áreas cercadas (Money, 2002, p. 85). É claro que os fungos são perfeitamente capazes de fazer esse trabalho por si próprios, com uma geografia mais aberta. E então nós, os amantes dos cogumelos, perambulamos, procurando a companhia de árvores e de cogumelos.

Os fungos nem sempre são benignos nas suas associações interespecíficas ${ }^{7}$. Os fungos são assustadoramente onívoros em seus hábitos de conversão de carbono. Vários fungos subsistem tanto de animais e plantas vivos como mortos. Alguns são ferozmente patogênicos (o Cryptococcus neoformans mata muitos pacientes de AIDS) (Money, 2002, p. 25). Alguns são parasitas irritantes (pense na frieira ou no pé de atleta). Alguns deslizam pelos intestinos de seus hospedeiros inocuamente esperando chegar a uma condição favorável para se multiplicar. Alguns fungos encontram substratos totalmente inesperados: Cladosporium resinae, originalmente encontrado em resinas de árvores, tomou gosto por combustível de aviões, causando o entupimento de tanques de combustível (Jennings; Lysek, 1999, p. 67-138). Alguns ferem um hospedeiro e vivem pacificamente com outro: Puccina graminis une-se ao arbusto de berberis e alimenta moscas com seu néctar de modo a produzir esporos que são mortíferos ao trigo quando nascem sobre ele (Money, 2002, p. 172-179). Os apetites fúngicos são sempre ambivalentes em sua benevolência, dependendo de nosso ponto de vista. A habilidade dos fungos de degradar a celulose e a lignina da madeira morta, tão temida pelos proprietários de casas de madeira, é também 
o maior presente dos fungos à regeneração florestal. Sem os fungos, a floresta estaria abarrotada de pilhas de madeira morta, e outros organismos teriam uma base de nutrientes cada vez menor. Assim, o papel dos fungos na renovação de ecossistemas torna mais do que óbvio que os fungos são sempre companheiros de outras espécies. A interdependência entre as espécies é um fato bem conhecido - exceto quando diz respeito aos humanos.

O excepcionalismo humano nos cega. A ciência herdou das grandes religiões monoteístas narrativas sobre a superioridade humana. Essas histórias alimentam pressupostos sobre a autonomia humana e levantam questões relacionadas ao controle, ao impacto humano e à natureza, ao invés de instigar questões sobre a interdependência das espécies ${ }^{\mathbf{8}}$. Uma das muitas limitações dessa herança é que ela nos fez imaginar as práticas de ser uma espécie (humana) como se fossem mantidas autonomamente e, assim, constantes na cultura e na história. A ideia de natureza humana foi apropriada por ideólogos conservadores e por sociobiólogos que se utilizam de pressupostos da constância e autonomia humanas para endossar as ideologias mais autocráticas e militaristas. E se imaginássemos uma natureza humana que se transformou historicamente com variadas teias de dependência entre espécies? A natureza humana é uma relação entre espécies. Longe de desafiar a genética, um recorte interespecífico para nossa espécie abre possibilidades de linhas de pesquisa tanto biológicas quanto culturais. É preciso entender mais, por exemplo, sobre as variadas teias de domesticação nas quais nós humanos nos enredamos.

A domesticação é geralmente compreendida como o controle humano sobre outras espécies. Que tais relações podem também transformar os humanos é algo frequentemente ignorado?. Além disso, tende-se a imaginar a domesticação como uma linha divisória: ou você está do lado humano, ou do lado selvagem. Pelo fato de essa dicotomia se basear num comprometimento ideológico com a supremacia humana, ela apoia as mais incríveis fantasias, por um lado, de controle doméstico e, por outro lado, de autoprodução das espécies selvagens. Por meio dessas fantasias, as espécies domésticas são condenadas à prisão perpétua e à homogeneização genética, enquanto 
as espécies selvagens são "preservadas" em bancos de germoplasma enquanto suas paisagens multiespécies são destruídas. Apesar desses esforços extremos, a maioria das espécies dos dois lados da linha, incluindo os humanos, vive em complexas relações de dependência e interdependência. Prestar atenção a essa diversidade pode ser o início da apreciação de um modo interespecífico de ser das espécies.

Fungos são espécies indicadoras da condição humana. Poucos fungos tiveram lugar nos esquemas humanos de domesticação e apenas alguns deles, como os fungos usados para produção industrial de enzimas, tiveram seus genomas seriamente alterados (os champignons do supermercado são o mesmo Agaricus bisporus que cresce nos campos). Os fungos são onipresentes, eles seguem todos os nossos experimentos e desvarios. Considere Serpula lacrymans, o fungo da podridão seca, que antes era encontrado apenas no Himalaia (Jennings; Lysek, 1999, p. 138). Em suas conquistas no sul da Ásia, a Marinha inglesa o incorporou em seus navios. S. lacrymans proliferou na madeira sem tratamento geralmente usada nos navios para campanhas navais, e assim viajou ao redor do mundo. No século XIX, o apodrecimento da madeira dos navios britânicos era chamado de "calamidade nacional" e o pânico perdurou até a introdução dos navios de guerra couraçados na década de 1860 (Ainsworth, 1976, p. 90-93). A podridão seca, entretanto, continuou se espalhando, pois o fungo encontrou novo lar nas vigas úmidas dos porões e nos dormentes das estradas de ferro da civilização patrocinada pelos britânicos. A expansão britânica e a podridão seca movimentaram-se juntas. Como nesse exemplo, a presença dos fungos geralmente nos fala sobre as mudanças nas práticas de ser humano. A domesticação dos humanos é um lugar por onde começar.

\section{A Origem da Família, da Propriedade Privada e do Estado ${ }^{10}$}

Os cereais domesticaram os humanos. O caso de amor entre as pessoas e os cereais é um dos grandes romances da história humana. Uma de suas formas mais extremas começou há mais ou menos dez mil anos no Oriente Próximo, em que as pessoas começaram a cultivar trigo e cevada. Na gênese dessa domesticação, trocaram o afeto às paisagens multiespécies pela intimidade com apenas um ou dois cultivares ${ }^{11}$. 
O mais curioso sobre a domesticação de grãos no Oriente Próximo é que na maioria de sua extensão era muito fácil coletar grandes quantidades de trigo e cevada selvagens sem o duro trabalho do cultivo. Mesmo na década de 1960, a grande quantidade de grãos selvagens fazia da coleta uma tarefa simples ${ }^{12}$. A história que contamos a nós mesmos sobre a "conveniência" e "eficiência" de plantar em casa simplesmente não é verdadeira. O cultivo quase sempre requer mais trabalho do que o forrageamento. Houve provavelmente muitas razões, da religião à escassez local, para se experimentar a domesticação. Porém, o que manteve e estendeu o cultivo de grãos foi a emergência das hierarquias sociais e a ascensão do Estado. A agricultura intensiva de cereais é bem-sucedida em um aspecto, em relação a outras formas de subsistência: o de apoiar as elites. Os Estados institucionalizam o confisco de uma porcentagem da colheita. Por toda a Eurásia, a ascensão dos Estados, e suas civilizações especializadas, foi associada à disseminação da agricultura intensiva de cereais. Em alguns lugares o Estado sucedeu a agricultura; em outros, a agricultura sucedeu os Estados. Em ambos os casos, os Estados promoveram a agricultura em suas insígnias e exércitos. Algumas vezes outras formas de subsistência foram criminalizadas: apenas os foras da lei recusariam a dádiva da fertilidade estatal. E para aqueles no coração do Estado, essa dádiva de fertilidade poderia se manter, pelo menos em tempos bons, pelo amor ${ }^{13}$.

A transformação biológica das pessoas e das plantas que acompanhou a agricultura intensiva de cereais pode ser entendida de melhor forma, portanto, por meio do advento dos arranjos sociais hierárquicos e pela constituição do Estado. Estados encorajam o estabelecimento de fazendas sedentárias e estáveis. O Estado incentivou unidades domésticas de base familiar e garantiu as formas de propriedade privada e herança que traçaram linhas dentro e entre famílias. O patriarca era o representante do Estado no nível da unidade de trabalho doméstica: era ele quem assegurava que os impostos e dízimos seriam recolhidos para a subsistência das elites. Foi no interior dessa configuração política que tanto as mulheres quanto os grãos foram confinados e manejados para maximizar a fertilidade ${ }^{14}$.

Os grãos selecionados por meio da domesticação eram sementes com alto teor de carboidratos. Dietas com alto teor de carboidratos 
permitiram às mulheres terem mais filhos. Ao invés de investirem em limitar a fertilidade, como fazem a maioria dos forrageadores, as pessoas repentinamente passaram a querer o número máximo possível de filhos, não apenas por conta do fetiche da fertilidade, mas também porque a família precisava de mais trabalho para os cereais. Os cereais não se importavam se o trabalho que os produziu era familiar ou extrafamiliar: não havia escassez de pessoas. Mas a propriedade apoiada pelo Estado incentivou o trabalho dentro da família, ou seja, o trabalho infantil. Ter muitos filhos não significava apenas deixar a natureza trabalhar: nem todos os animais trabalham para maximizar a reprodução. A reprodução humana fora de controle e não sustentável é uma característica de uma domesticação humana em especial: o caso de amor entre as pessoas e os grãos de cereais. Essa obsessão pela reprodução, por sua vez, limitou a mobilidade das mulheres e suas oportunidades para além do cuidado com as crianças. Apesar das possibilidades matriarcais criadas por esse processo, parece justo chamar esse caso de amor interespecífico de "a derrota histórica do sexo feminino"15.

Ao intensificarem seus esforços para alimentar populações humanas cada vez maiores, os agricultores se concentraram num conjunto cada vez menor de plantas e para um conjunto ainda menor de formatos de família. Entretanto, a padronização dos cultivos e de suas famílias humanas não se completou em nenhum lugar. Onde quer que o poder do Estado tenha se atenuado, paisagens de maior biodiversidade e de maior diversidade social continuaram a proliferar. Entretanto, o modelo idealizado de confinamento padronizado foi uma força poderosa por si mesma para manter as margens na marginalidade. Durante minha pesquisa com agricultores itinerantes de Kalimantan, Indonésia, algumas mulheres falavam de minha riqueza e de meus privilégios: "Se eu tivesse o que você tem, meus pés nunca tocariam o chão". O confinamento das mulheres é a base de um belo sonho de ordem e plenitude.

Os fungos são inimigos da monocultura e dos monocultores. Desde que os Estados antigos incentivaram a agricultura intensiva, houve muitas e variadas pressões para padronizar os cultivares. Desde o século XIX, a agricultura científica suplantou os esforços de padronização das 
primeiras domesticações. Ela transformou a padronização em si no "padrão moderno"16. Atualmente, apenas a padronização permite aos agricultores comercializar sua produção. Entretanto, a padronização torna as plantas vulneráveis a todo tipo de doença, incluindo aquelas causadas por fungos, conhecidas como ferrugens e carvões. Sem chances de desenvolver variedades resistentes, uma lavoura atacada pode morrer toda de uma só vez. A emergência de vastos campos de grãos prestou-se, portanto, a oferecer um banquete aos fungos fitoparasitas e a criar sua reputação de inimigos da civilização e, posteriormente, do progresso. Como o cultivo de não cereais foi moldado nos ideias da lavoura intensiva de cereais, essas lavouras também sucumbiram a todo tipo de doenças causadas por fungos: um aviso a todos nós.

A catástrofe fúngica mais famosa é provavelmente a peste da batata irlandesa. As batatas eram cultivadas na Irlanda com um zelo monocultor, forjado na imagem reversa da expansão dos grãos provocada pelo Estado. A colonização britânica relegou aos irlandeses as terras mais marginais. Incursões militares queimaram e confiscaram lavouras de grãos. Foram os tubérculos subterrâneos que permitiram a sobrevivência dos irlandeses. No final do século XVIII, as batatas haviam se tornado a base da dieta dos irlandeses. Quando os senhores de terras, por motivações políticas, abriram novas terras para arrendatários as cultivarem, proliferaram pequenos sítios. As famílias dos arrendatários, providos de batatas, casaram-se mais cedo e tiveram mais filhos. Mesmo com a economia abalada pelo controle colonial, a população humana cresceu de cinco para oito milhões de habitantes em 50 anos, levando as pessoas a depender das batatas em sua alimentação. (Salaman, 1985 [1949]). Mas a monocultura cobra seu troco. Os europeus haviam importado apenas algumas das milhares de variedades de batata domesticadas pelos sul-americanos ${ }^{17}$.

Phytophtora infestans, o míldio da batata, foi registrado a primeira vez em 1835 como um problema local na Inglaterra. O fungo desenvolveu-se lentamente até o verão chuvoso e abafado de 1845, quando repentinamente todas as plantas da Irlanda estavam infectadas, assim como todas as batatas armazenadas. O resultado foi que um milhão de pessoas passaram fome e talvez dois milhões tenham emigrado 
para os Estados Unidos ${ }^{18}$. Como a manipulação genética e a clonagem passaram a afetar mais e mais cultivos, o alarme fúngico soa continuamente. Considere as plantações de acácia pelas quais nossos perspicazes agentes do desenvolvimento pensaram poder substituir as florestas do Bornéu: produzidas a partir de um único clone, são uniformemente suscetíveis a um fungo que devora e torna ocos seus troncos (Brookfield et al.,1995, p. 105). Porque alguém imaginaria plantá-los dessa foram é outra história - que nos leva à dinâmica da conquista e expansão europeia.

A empresa monocultora foi o motor da expansão europeia. As chamadas plantations produziram a riqueza - e o modus operandique permitiu aos europeus dominarem o mundo. Fala-se em tecnologias e recursos superiores, mas foi o sistema de plantation que tornou possível as frotas marítimas, a ciência e mesmo a industrialização. As plantations são sistemas de plantio ordenado realizado por mão de obra de não proprietários e direcionados à exportação. As plantations aprofundam a domesticação, reintensificando as dependências das plantas e forçando a fertilidade. Tomando de empréstimo da agricultura de cereais promovida pelo Estado, investiu-se tudo na superabundância de uma só lavoura. Mas faltou um ingrediente: removeu-se o amor. Ao invés do romance conectando as pessoas, as plantas e os lugares, os monocultores europeus nos apresentaram o cultivo pela coerção ${ }^{19}$. As plantas eram exóticas; o trabalho era realizado à força por meio da escravidão, de contratos e de conquista. Apenas por meio de ordenamento e controle extremos algo poderia frutificar dessa maneira; mas com hierarquia e antagonismo administrado em campo, lucros enormes (e misérias complementares) puderam ser produzidos. Como as plantations formataram a maneira como o agronegócio contemporâneo é organizado, tendemos a pensar em tais arranjos como a única maneira de praticar agricultura. Mas esse arranjo teve de ser naturalizado até que aprendêssemos a levar em conta a alienação das pessoas em relação às suas lavouras.

Considere a cana-de-açúcar, uma participante-chave. Ninguém ama a monocultura de cana. O trabalhadores da cana em Porto Rico saem para "se defender" e "brigar" com a cana (Mintz, 1974, p. 16) ${ }^{\mathbf{2 0}}$. 
Contudo, entre os séculos XVII e XIX, as lavouras de cana-de-açúcar produziram a riqueza que abasteceu a conquista e o desenvolvimento europeus.

A cana foi transportada através das zonas quentes, redefinindo regiões; e atrás dela vieram proprietários, administradores e trabalhadores $^{21}$. Escravos foram levados da África Ocidental para o Novo Mundo. Trabalho precário coolie da Índia e da China penetrou o Pacífico. Camponeses foram dominados e coagidos nas Índias. E ao forjar um novo antagonismo com as plantas das monoculturas, os seres humanos modificaram a natureza de ser espécie. As elites estabeleceram seu senso de autonomia com relação às outras espécies: eles eram senhores e não amantes dos seres não humanos, ou seja, das espécies outras que vieram ao mundo para definir a autoatribuição humana. Mas para os monocultores isso só era possível na medida em que uma subespécie humana era formulada e produzida à força: alguém tinha que trabalhar na lavoura de cana. A biologia veio a significar a diferença entre proprietários livres e trabalhadores submetidos. As pessoas de cor trabalhavam nos canaviais; as pessoas brancas apenas os possuíam e administravam. Não havia lei ou ideal que parasse a miscigenação, mas garantia-se que apenas a raça branca podia herdar propriedades. As divisões raciais foram produzidas e reproduzidas a cada dote ou herança ${ }^{22}$.

Desde o início os fungos estavam lá, prontos para preencherem os eventuais nichos. Os fungos limitaram a lavoura de cana dos pequenos proprietários. Depois do corte, a cana deve ser processada imediatamente para evitar a fermentação por fungos. A enorme escala dos canaviais e sua disciplina selvagem de trabalho são em parte uma resposta aos temores da fermentação, o que inspirou a construção de dispendiosos engenhos nas fazendas - e o desejo de mantê-los funcionando continuamente. No entanto, a fermentação por fungos acabou se tornando uma dádiva aos monocultores. Não demorou para os canavieiros caribenhos perceberem que o melaço, um subproduto do processamento do açúcar, ao reagir com os onipresentes esporos de leveduras, rapidamente se transformava em álcool. Assim nasceu o rum. E o mortífero, porém, lucrativo "comércio triangular" ofertou 
rum em troca de mais escravos africanos e assim houve maior produção de açúcar e assim surgiram mais destilarias e financiadores na Inglaterra ou na Nova Inglaterra. Posteriormente, o açúcar veio a se tornar um objeto e símbolo do consumo em massa, assim cimentando as expectativas do público de uma espécie autônoma que se alimentava de comida cuja espécie não pode ser reconhecida, que misteriosamente aparecia do além. Muito antes disso, entretanto, o rum de fermentação fúngica havia tornado a plantation canavieira lucrativa, disseminando-a ao longo do campo da Conquista europeia ${ }^{23}$.

Nos limites da respeitabilidade, o rum abasteceu masculinidades marítimas pelas quais o comércio tornou-se aventura. A fermentação, assim, tirou a atenção das pessoas da crueldade da domesticação litorânea, tanto humana quanto não humana.

As mulheres brancas tornaram-se agentes da higiene racial. Dividindonos firmemente em raças, as monoculturas refizeram o que é ser da espécie humana, a prática de ser um humano. A separação racial, dependendo se feita no casamento ou na organização familiar, requereu transformações adicionais de gênero. Nas regiões das plantations, com suas misturas não estabilizadas entre o que é nativo ou estrangeiro, o que é livre, dependente ou escravizado, do selvagem e do domesticado, da doença e da plenitude, as coisas podiam facilmente dar errado.

Aqui as mulheres brancas se tornaram responsáveis por manter as fronteiras, seja das casas, das famílias, das espécies e da raça branca. Os fungos tropicais eram uma pequena parte do problema; o mofo e as infecções podiam sair de controle. Mantendo suas casas livres de mofo, mosquitos e miscigenação, as mulheres brancas nos trópicos se tornaram modelos da alienação de espécies e subespécies ${ }^{24}$.

No século XIX, os discursos de higiene científica e eugenia informaram as segregações de espécie das mulheres brancas. A teoria dos germes de Pasteur foi testada e fomentada nos Trópicos, em que certos espaços controlados pelos brancos puderam ser organizados como laboratórios, com microorganismos barrados nas fronteiras dos lares brancos. As mulheres brancas foram chamadas a seguir de seus maridos aos Trópicos para manter as coisas limpas ${ }^{25}$. Reimportada pelas Metrópoles, tal higiene pública e privada alimentou as dicotomias de 
classe, informando distinções previamente existentes entre mulheres "doentes" e mulheres "contagiosas" (Ehrenreich; English,1973). As mulheres de alta classe se tornaram vulneráveis anjos do lar, enquanto as mulheres pobres eram acusadas de agentes de infecções. Ambas receberam ordens renovadas de reprodução. As famílias pobres precisavam de mais força de trabalho, particularmente quando o trabalho infantil permitiu a sobrevivência de muitos adultos ${ }^{26}$. Já as famílias com privilégios se fortaleceram com o avanço da ideia de raça, já que as mulheres tinham de gerar seus herdeiros.

As fronteiras do lar se tornaram as expectativas das fronteiras esperadas para o amor. Com a fetichização do lar como espaço de pureza e interdependência, as intimidades extradomésticas, sejam internas à espécie ou entre espécies, pareciam fantasias arcaicas (a comunidade, o sitiante) ou questões passageiras (feminismo, direitos animais). Fora de casa reinavam o domínio da racionalidade econômica e os interesses individuais conflitantes. Além disso, esse tipo de fetiche familiar reapareceu na cultura de massa de meados do século XX nos Estados Unidos - e novamente hoje em dia - quando os EUA assumiram a liderança global que permitiu sobrepujar os regimes mais antigos de cultura colonial. Aqui não se espera amor fora dos muros familiares. No seio da família, outras espécies podem ser aceitas. Animais de estimação são modelos da devoção familiar. Mas o modelo dos tão amados pets não dissemina o amor: ele mantém o amor amarrado ao interior da família.

A opinião pública estadunidense aprendeu a imaginar-se como pessoas morais e piedosas porque amam suas crianças e seus animais de estimação. As pessoas aprendem que este amor os torna "pessoas boas", ao contrário dos terroristas, que fazem apenas odiar. Elas imaginam que o amor as capacita para tomarem decisões em nome de todo o mundo. Cria-se uma hierarquia moral na qual a "bondade" americana se torna qualificação para a liderança global. Outros povos e outras espécies são julgados por sua habilidade de sobreviver a padrões americanos de intimidade doméstica. Se estiverem propriamente envolvidos com o amor familiar, merecem viver. Outros riscos tornamse "efeitos colaterais" dos projetos estadunidenses para melhorar o 
mundo. Eliminar tais riscos pode ser algo infeliz, mas não "desumano". Sob tal tutela, nossa forma de ser uma espécie é realinhada para barrar os Outros na porta de casa.

Dados o poder e a capacidade de disseminação deste plano biossocial, é incrível que uma (ainda) rica diversidade de espécies e populações ainda continue a existir na Terra. Mas a existência de tal riqueza não pode mais ser tomada como um pressuposto.

\section{Coleta de Cogumelos nas Costuras do Império}

A diversidade, biológica e social, se amontoa defensivamente em margens despercebidas. Em selvas urbanas, bem como nos recantos rurais, ainda fervilha o amontoado de diversidade que os planejadores imperiais tendem a considerar excessiva. Os pequenos agricultores convivem com uma diversidade biológica significativamente maior do que o fazem as grandes fazendas de capital intensivo, e não apenas em suas lavouras. Mesmo os fungos do solo e outros microorganismos preferem pequenas propriedades (Vandermeer; Perfecto, 1995). Apesar do ritmo frenético do comércio genético, os processos evolutivos em zonas despercebidas continuam a produzir mais espécies úteis e interações entre espécies em muitas ordens de magnitude. Os fungos são representativos.

Que ser é capaz de se desenvolver em áreas de mineração contaminadas? Muitos cogumelos de micorrizas, da guloseima Laccaria laccata aos perturbadores Pisolithus tinctorius, acumulam metais pesados, protegendo os seus parceiros florestais, as plantas, da contaminação ${ }^{27}$ (Dighton, 2003, p. 323-339). Novos fungos radioativos colonizaram as paredes da sala do reator nas ruínas de Chernobyl. Se alguém decidir sequestrar a radioatividade, tais espécies serão necessárias (Dighton, 2003, p. 350-351). Claro que nem todo o desenvolvimento das espécies de fungos é benigno, mas é apenas na profusão confusa da diversidade que é possível a adaptação. De fato, na maioria dos lugares existe uma correlação negativa entre, de um lado, a diversidade e, de outro, a intensidade de investimento de capital e controle do Estado. Para aqueles que amam a diversidade, talvez seja necessário um projeto de desmapeamento do Capital-Estado. 
Tais projetos operam melhor na obscuridade que eles procuram espalhar. Para trabalhos que intencionam publicidade, deveríamos procurar saber algo do ponto de vista das bordas produtivas e desordenadas: as costuras do império.

Os cogumelos que comemos se reúnem nas bordas. Os fungos são onipresentes, mas os cogumelos comestíveis e medicinais só crescem em poucos lugares. Muitos cogumelos valiosos desenvolvem-se em ambientes agrários equivalentes a costuras: nos limites entre campos e florestas, nas margens das zonas de cultivo. Os tortulhos e os cantarelos são espécies da floresta e de bordas de trilhas; eles gostam de luz, mesmo à medida que crescem junto com as árvores. Outros, como o cogumelo do prado (Agaricus campestris), preferem os campos abandonados. Esses cogumelos ainda nos lembram dos prazeres da variedade que existe para além do doméstico. Enquanto isso, muitas espécies são abundantes nas florestas e nas montanhas que circundam vales intensamente agrários.

Desde tempos antigos, os coletores de cogumelos têm vasculhado as bordas das montanhas e das florestas dos reinos granívoros: no sudoeste da China e no Sudeste Asiático adjacente; na Coreia; na Europa Oriental; e no norte da Eurásia. Na América do Norte contemporânea, imigrantes dessas regiões agrárias marginais continuam a coletar cogumelos para o mercado. Enquanto isso, o mercado mundial de cogumelos distribuiu sua coleta por todo o mundo. O matsutake, uma iguaria japonesa, leva coletores não só para as margens asiáticas tradicionais, mas também para as margens montanhosas do outro lado do Pacífico: a Colúmbia Britânica, o Noroeste dos EUA e as montanhas de Oaxaca ${ }^{28}$.

A coleta comercial de cogumelos nos permite ver as costuras do capitalismo global. Não se trata apenas de lugares diferenciados e produtos específicos; as formas de conhecimento e de gestão de recursos também são extremamente divergentes, conectadas apenas de maneira temporária na cadeia de commodities de cogumelo. Famílias do Sudeste Asiático competem por territórios em Oregon. Connoisseurs japoneses desenvolvem hierarquias regionais de gosto. Há muita contingência e variação aqui para imaginar um simples cálculo de oferta 
e demanda. A imersão neste espaço não remove ninguém do mundo do capital, das classes e da regulação. Aqui não há espaço para uma busca por utopia. Mas perceber as costuras é um lugar para se começar (Tsing, 2005).

Em casas protegidas ao longo de todo o império, os seres humanos se acomodam em suas poltronas com seus animais de estimação e seus biscoitos que imitam espécies para assistir à destruição do resto do mundo na TV. É difícil saber se algum ser humano vai sobreviver a tais sonhos domésticos. Os fungos não estão se posicionando. Mesmo os líquens resistentes estão morrendo por causa da poluição do ar e da chuva ácida (Dighton, 2003, p. 322). Quando eles captam a radioatividade dos acidentes nucleares, eles a ofertam como alimento para as renas, que por sua vez alimentarão os humanos caçadores. Nós podemos ignorá-los, ou podemos considerar o que eles estão a nos dizer sobre a condição humana (Dighton, 2003, p. 352-353).

Fora de casa, entre as florestas e os campos, a recompensa ainda não se esgotou.

Agradecimentos: este ensaio foi originalmente escrito para uma coletânea que nadou por muitos anos antes de morrer na praia. O ensaio teve uma vida relativamente longa, até então circulando como manuscrito. Donna Haraway compartilhou uma leitura crítica generosa, trazendo ao texto novos níveis de significado. Diane GiffordGonzalez e S. Eben Kirksey gentilmente comentaram sobre o projeto inicial. Eu me beneficiei de suas leituras. Os erros são de minha autoria.

Anna Tsing é Professora Niels Bohr na Universidade Aarhus, Dinamarca, onde coordena o projeto "Aarhus University Research on the Anthropocene" (AURA). É também professora de antropologia na Universidade da Califórnia, Santa Cruz, EUA. É co-editora de diversas coletâneas (a mais recente é "Words in Motion", com Carol Gluck) e autora dos livros "In the realm of the Diamond Queen: marginality in an out-of-the-way place" e "Friction: an ethnography of global connection". Seu último livro chama-se "The mushroom at the end of the world: on the possibility of life in capitalist ruin" (2015) e foi elaborado a partir das reflexões deste ensaio sobre a vida multiespécies e a história do mundo por meio dos cogumelos. 


\section{Notas}

1 Este artigo foi originalmente publicado como "Unruly Edges: Mushrooms as Companion Species", em Environmental Humanities, v. 1, de novembro de 2012.

2 Haraway expande o termo "animal de companhia", usado pelos amantes dos animas de estimação, para falar sobre relacionamentos interespécies.

3 Nota dos tradutores: optamos, sempre que possível, por traduzir para o português os nomes populares dos fungos e plantas citados ao longo do texto. A maior parte dos cogumelos comestíveis citados não tem um nome popular no Brasil. Assim, optamos por usar nomes como são conhecidos em Portugal. De qualquer forma, priorizamos mencionar também os nomes científicos das espécies, para facilitar seu reconhecimento por um leitor especialista.

4 "Em nome de Deus, o mais benevolente e o mais misericordioso".

5 Estudos recentes sobre o mutualismo entre espécies enfatizam o trabalho ativo e estratégico de todas as espécies envolvidas. Por exemplo, estudos de bactérias fixadoras de nitrogênio nos nódulos radiculares de soja mostram que a soja dificulta o desenvolvimento de linhagens bacterianas que oferecem menos nitrogênio, ao limitar a elas o oferecimento de oxigênio. (Kiers et al., 2003, p. 78-81).

6 As orquídeas foram moda na botânica do século XIX. As micorrizas foram apreciadas pela primeira vez por cientistas ocidentais quando se descobriu que muitas orquídeas dependem de seus parceiros fúngicos (Ainsworth, 1976, p. 102-104).

7 O termo fungos refere-se a uma classificação biológica maior (um reino, a exemplo do reino das plantas e o dos animais, entre outros), dos quais cogumelos formam uma parte. Todos os cogumelos são fungos, porém nem todos os fungos produzem cogumelos.

8 Uma importante exceção a esta generalização é a literatura médica e ecológica sobre as doenças e parasitas humanos, em que a coexistência de espécies é uma preocupação central. Na medida em que as outras espécies relevantes são encontradas, em geral, dentro do corpo humano, podemos estudá-las em relações de coabitação e dependência. No entanto, essa exceção reafirma o problema. Se a outra espécie está fora do corpo humano, isto é, como parte do "ambiente" dos humanos, as análises subitamente mudam para um discurso do impacto, gestão e controle humanos.

9 O trabalho de Haraway (2003) sobre os cães representa uma quebra nesta linha de pensamento.

${ }^{10}$ A já clássica história contada por Engels enfatiza o papel do pastoralismo no desenvolvimento de noções de propriedade privada. A primeira propriedade, argumenta ele, foi a de rebanhos (Engels, 1972). Noções de propriedade utilizadas para regular a reprodução de rebanhos inspirou o controle masculino da reprodução em famílias humanas, inaugurando "a histórica derrota mundial do sexo feminino". Pensadoras feministas como Eleanor Leacock e Evelyn Reed trouxeram este clássico de volta à circulação na década de 1970, quando ele provocou discussões acaloradas sobre a longa história de desigualdade social, particularmente no campo da antropologia feminista. Veja-se, por exemplo, Reiter (1975); Rosaldo e Lamphere (1974); Etienne e Leacock (1980); e a introdução de Leacock em Engels (1967:7-67). Em meados da década de 1980, a antropologia feminista debruçou-se cada vez mais na especificidade da pesquisa etnográfica para saber mais sobre a construção cultural de gênero. Se esta virada levou a muitos insights importantes, também deixou o campo das narrativas da história de longa duração para os misóginos, incluindo os sociobiólogos, médicos e escritores de ficção científica, a maioria dos quais não 
são bem familiarizados com leituras em história ou em antropologia. Talvez seja a hora das feministas retornarem a esse debate.

11 A transição de um foco em paisagens para um foco em lavouras deve ser longa e incompleta. O manejo de paisagens multiespécies para favorecer certos animais de caça ou plantas silvestres foi muitas vezes um passo para a domesticação (Brookfield, 2001, p. 64-69). Além disso, o foco no forrageamento multiespécies de amplo espectro pode ser visto por si mesmo como um produto histórico. No Oriente Próximo, a transição para a coleta de uma variedade de pequenas sementes de gramíneas é associada a um período de 10 mil anos antes da domesticação (Weiss et al., 2004: 9551 -555).Também não é justo imaginar que a domesticação limitou a atenção dos agricultores para apenas uma ou duas lavouras. As domesticações no Oriente Próximo produziram legumes, plantas fibrosas e verduras, tanto quanto os diversos tipos de grãos de cereais. Algumas destas plantas vieram à atenção dos agricultores primeiro como as ervas daninhas, tendendo a assumir um estatuto secundário no manejo dos campos. O trigo e a cevada estabelecerem sua proeminência e ganhou lugar de destaque nos corações dos agricultores.

12 O cientista Jack Harlan realizou um experimento de colher trigo selvagem do Oriente Próximo usando uma foice de lâmina de sílex modelado como as ferramentas antigas. Ele recolheu o equivalente a um quilograma por hora de grão limpo e altamente nutritivos (Harlan, 1975, p. 12,172).

${ }^{13}$ Richard O'Connor (1995, p. 968-996) argumenta que a agricultura intensiva de arroz foi o elemento fundamental para permitir a formação do Estado no Sudeste Asiático. "Negara", de Clifford Geertz (1980), ilustra a prática autônoma da agricultura intensiva de arroz na Bali pré-colonial. Em Bali o poder do Estado não significou controle nos arranjos de irrigação, mas sim da estrutura estética de poder e amor. Eu mesma mostrei como a expansão do Estado criou paisagens intensivas de grãos no Sudeste da Ásia (Greenough; Tsing, 2003, p. 124-169).

14 A natureza ambígua desta forma de amor é sugerida pelo fato de que antigos plantadores de grãos do Oriente Próximo terem sido associados com a aproximação de uma religião "matriarcal" sugerida por muitos historiadores. A fetichização de reprodução tornou mulheres férteis ícones do sagrado. Outros talentos potenciais das mulheres não devem ter sido, entretanto, igualmente apreciados, levando ao sofrimento as mulheres estéreis.

15 Ver nota 10. Seria incorreto imaginar que o confinamento das mulheres associado à agricultura cerealista iniciou um tempo de maior facilidade para o sexo feminino. Pelo contrário, para o trabalho de processamento da colheita, especialmente de grãos, seja para comida ou para armazenamento, foram necessários cada vez mais investimentos da mão de obra feminina.

${ }^{16}$ Jan van der Ploeg (1993, p. 209-227) descreve o ponto de partida da moderna ciência agrícola como um "tipo ideal de planta". Esse ideal estabelece um padrão de superioridade, organiza a reprodução, e exige um refazer de toda a operação agrícola para atender as suas necessidades. Van der Ploeg contrasta a ciência da padronização de batatas com o conhecimento local sobre batatas nos Andes que, em contraste, permite a heterogeneidade.

17 Salaman (1985) [1949]), no Capítulo X de sua obra, elabora um relato sobre as importações europeias e as variedades desenvolvidas a partir delas. Após a fome irlandesa, novas variedades foram multiplicadas pelos criadores europeus buscando maior resistência. No entanto, o objetivo sempre foi o de encontrar a melhor variedade, em vez de incentivar a diversidade no campo. Em contraste, Jonathan 
Sauer (1993, p. 145-155), discute os cultivares sul-americanos. Observando a ainda grande diversidade varietal na agricultura de subsistência, ele escreve: “Uma aldeia pode ter mais de 100 clones com nomes reconhecidos por toda a aldeia" (p. 148). Sobre o míldio da batata, ele comenta: "Assim como outros parasitas de sucesso, o fungo não é, aparentemente, fatal, onde ele e seus hospedeiros têm um tempo longo de coexistência. A praga foi reconhecida como um problema na América do Sul somente após o desenvolvimento da monocultura da batata comercial, por exemplo, no Chile e no Peru, em cerca de 1950". (p. 152).

18 A praga afetou toda a Europa, mas apenas a Irlanda foi devastada porque apenas a Irlanda era completamente dependente das batatas (Salaman, 1985 [1949], Capítulo XVI; Jennings e Lysek, 1999, p. 136; Money, 2002, p. 184-186; Christensenet, 1965, p. 98-103).

19 O sistema de plantation patrocinado pelos europeus também transferiu a força do controle da expansão agrícola dos Estados para os interesses do Capital, estabelecendo assim o primeiro contexto para a hegemonia política do Capital. Este foi um processo longo e confuso e a maioria das histórias do mundo imperial do século XVI ao século XIX é repleta de debates entre monocultores, mercantilistas, traficantes de escravos, administradores coloniais e proponentes de "livre comércio". Por meio de tais debates é que tal mudança foi tortuosamente negociada. Cada vez mais o lucro, ao invés do Estado, tornou-se o objetivo do desenvolvimento agrícola.

${ }^{20}$ Em contraste com as batalhas que acontecem nas plantations, a cana-de-açúcar numa economia familiar é um objeto de amor. Nas terras altas do Sudeste da Ásia, por exemplo, a cana é um refresco doce, não uma corrida para a refinaria. O antagonismo entre a cana e os humanos não é inerente à natureza da cana.

${ }^{21}$ Sauer (1993, p. 236-250) traça as viagens dos humanos e não humanos pelo mundo na história do cultivo da cana. Formaram-se novas geografias de tipos de cana e tipos humanos. Pragas fúngicas foram participantes importantes destas jornadas: em 1882, por exemplo, a "podridão vermelha" foi introduzida nas plantações das Índias Ocidentais de forma episódica, com o recebimento de uma amostra de cana enviada das Ilhas Maurício. (Galloway, 1989, p. 141).

22 Verena [Stolcke] Martinez-Alier ( 1989) detalha como tal sistema foi desenvolvido em Cuba em resposta ao boom do açúcar do século XVIII, que multiplicou as fortunas dos monocultores e levou um grande número de escravos para a ilha. A raça, argumenta ela, veio para ficar na divisão de trabalho das plantations da Cuba do século XIX.

23 Sidney Mintz (1985) traça a história do açúcar, mostrando como ele se tornou um objeto de consumo disseminado na Inglaterra apenas no século XVIII, bem depois que o "comércio triangular", estimulado pelo rum, foi estabelecido. Ele também mostra como os canaviais caribenhos formaram um modelo de trabalho protoindustrial que moldou a nascente industrialização na Europa, com as suas formas sociais, bem como a sua riqueza.

${ }^{24}$ Como "os trópicos" passaram a ser definidos em termos de problemas médicos e de higiene racial, as mulheres brancas foram requisitadas a assumirem um papel maior na manutenção de famílias saudáveis, além da manutenção da raça branca. Arnold (1996) discute a formação colonial nos trópicos. Ann Stoler (2002) mostra como a transformação de gênero foi chave para as ideologias emergentes sobre raça e sobre medicina.

25 Como explica Bruno Latour (1986), o principal problema para demostrar a importância da teoria pasteuriana dos germes foi a necessidade da criação das condições 
de higiene como as de laboratório nas quais as pessoas e seus seres domesticados poderiam ser mantidos longe do ambiente geralmente saturado de microorganismos patogênicos. Latour sugere que os exércitos coloniais nos trópicos, onde as doenças corriam desenfreadas, limitando a conquistas coloniais, foram os primeiros laboratórios vivos para a medicina pasteuriana. Warwick Anderson (2003) discute a aplicação das teorias higienistas no governo colonial nos trópicos. Ann Stoler (2002) mostra a centralidade da importação de mulheres brancas para os trópicos como parte da nova eugenia do período colonial tardio.

${ }^{26}$ Nos canaviais baseados em trabalho camponês das Índias Orientais Holandesas, por exemplo, as famílias precisavam de trabalho tanto para produção de arroz para subsistência quanto para o trabalho contratado da cana. O tamanho das famílias rapidamente disparou em resposta a tais demandas de trabalho coloniais. Havia muita gente, mas por conta das famílias serem unidades de trabalho compulsório, cada família precisava de sua própria mão-de-obra. O trabalho infantil geralmente era a base de toda família. Benjamin White (1982, p. 18-31) resume sua pesquisa e a dos outros sobre essa questão em Agricultural Involution' and its Critics: Twenty Years After, no sentido de que as explosões populacionais em todo o Sul colonial devem ser consideradas em relação às demandas extorsivas das plantations.

27 Alguns fungos desenvolvem "radiotropismo", ou seja, direcionam seu crescimento para as fontes de radioatividade!

28 O grupo de pesquisa "Matsutake Worlds" (Tim Choy, Lieba Faier, Michael Hathaway, Miyako Inoue, Shiho Satsuka e eu mesma) formou-se em 2005 para dar conta de algumas questões levantadas nesse ensaio. Para alguns mundo em que tivemos o privilégio de adentrar, consulte <http://www.matsutakeworlds.org/>.

\section{Referências}

AINSWORTH, G. C. Introduction to the History of Mycology. Cambridge: Cambridge University Press, 1976.

ANDERSON, W. The Natures of Culture: Environment and Race in the Colonial Tropics. In Nature in the Global South, edited by Paul Greenough and Anna Tsing. Duke University Press, 2003. p. 29-46.

ARNOLD, D. The Problem of Nature: Environment, Culture and European Expansion. Oxford: Blackwell, 1996.

BROOKFIELD, H. Exploring Agrodiversity. New York: Columbia University, 2001.

BROOKFIELD, H.; POTTER, L.; BYRON, Y. Place of the Forest:

Environmental and Socioeconomic Transformations in Borneo and the Eastern Malay Peninsula. New York, United Nations Press, 1995.

CHRISTENSEN, C. M. The Molds and Man. Minneapolis: University of Minnesota Press, 1965.

DIGHTON, J. Fungi in Ecosystem Processes. New York: Marcel Dekker, 2003. 
EHRENREICH, B.; ENGLISH, D. Complaints and Disorders: The Sexual Politics of Sickness. Old Westbury, NY: The Feminist Press, 1973.

ENGELS, F. The Origin of the Family, Private Property, and the State. New York: International Publishers, 1972.

ETIENNE, M.; LEACOCK, E. (Ed.).Women and Colonization:

Anthropological Perspectives. New York: Praegor, 1980.

GALLOWAY, H. The Sugar Cane Industry. Cambridge: Cambridge University Press, 1989.

GEERTZ, C. Negara. Princeton: Princeton University Press, 1980.

HARLAN, J. Crops and Man. Madison, Wisconsin: American Society of Agronomy and Crop Science Society of America, 1975.

HARAWAY, D. The Companion Species Manifesto: Dogs, People, and Significant Others. Chicago: Prickly Paradigm, 2003.

JENNINGS, D. H.; LYSEK, G. Fungal Biology. 2. ed. Oxford: Bios Scientific Publishers, 1999.

KIERS, E. et al. Host Sanctions and the Legume-Rhizobium Mutualism. Nature, [S.1.], v. 425, n. 4, p. 78-81, 2003.

LATOUR, B. The Pasteurization of France. Translated by Alan Sheridan and John Law. Cambridge: Harvard University Press, 1986.

LEACOCK, E. Introduction. In: ENGELS, Frederick. The Origin of the Family, Private Property, and the State. New York: International Publishers, p. 7-67, 1972.

MARTINEZ-ALIER, V. Marriage, Class, and Colour in NineteenthCentury Cuba. Ann Arbor: University of Michigan Press, 1989.

MINTZ, S. Worker in the Cane. New York: W. W. Norton and Co., 1974. . Sweetness and Power: the place of sugar in modern history. New York: Penguin Books, 1985.

MONEY, N. Mr. Bloomfield's Orchard. Oxford: Oxford University Press, 2002.

O'CONNOR, R. Agricultural Change and Ethnic Succession in Southeast Asian States: a case for a Regional Anthropology. The Journal of Asian Studies, [S. 1.], v. 54, n. 4, p. 968-996, 1995.

REITER, R. (Ed). Toward an Anthropology of Women. New York: Monthly Review, 1975.

ROSALDO, M.; LAMPHERE, L. (Ed.). Woman, Culture, and Society. Stanford: Stanford University Press, 1974. 
SALAMAN, R. The History and Social Influence of the Potato.

Cambridge: Cambridge University Press, 1985 [1949].

SAUER, J. Historical Geography of Crop Plants. Boca Raton: CRC Press, 1993.

STOLER, A. Carnal Knowledge and Imperial Power: race and the intimate in colonial rule. Berkeley: University of California Press, 2002. TSING, A. Agrarian Allegories and Global Futures. In: TSING, A. Nature in the Global South, edited by Paul Greenough and Anna Tsing. Duke University Press, 2003. p. 124-169.

. Friction: an ethnography of global connection. Princeton:

Princeton University Press, 2005.

VANDERMEER, J.; PERFECTO, J. Breakfast of Biodiversity: the truth about rain forest destruction. Oakland: Institute for Food and Development Policy, 1995.

VAN der PLOEG, J. D. Potatoes and Knowledge. In: VAN der PLOEG, J. D. An Anthropological Critique of Development, edited by Mark Hobart. London: Routledge, 1993. p. 209-227.

WEISS, E. et al. The Broad-Spectrum Revisited: Evidence from Plant Remains. Proceedings of the National Academic of Sciences, USA, v. 101, n. 29, June, p. 9.551-9.555, 2004.

WHITE, B. Agricultural Involution and its Critics: Twenty Years After.

Bulletin of Concerned Asian Scholars, [S.1.], v. 15, n. 2, p. 18-31, 1982.

Recebido em 10/03/15

Aceito em 03/04/15 